\title{
Chlorococcales planctônicas do Rio São João, Parque Nacional do Iguaçu, Paraná, Brasil
}

\author{
Jascieli Carla Bortolini ${ }^{1}$, Thamis Meurer ${ }^{1}$, Luciana Rufino Godinho ${ }^{2}$ e Norma Catarina Bueno ${ }^{1,3,4}$
}

Recebido: 13.08.2009; aceito: 13.05.2010

\begin{abstract}
Planktonic Chlorococcales of the São João River, Iguaçu National Park, Paraná, Brazil). This paper represents a floristic survey of the algal species in the order Chlorococcales (Chlorophyceae) from the São João River, Iguaçu National Park, Foz do Iguaçu, Paraná, Brazil. Samples were collected from June 2008 to May 2009 at three sampling stations along the riverbed. The phytoplankton material obtained with a $25 \mu \mathrm{m}$ nylon plankton net was immediately fixed on Transeau solution. The qualitative analyses of the samples resulted in the identification of 28 taxa distributed among the families Hydrodictyaceae, Oocystaceae, and Scenedesmaceae. The most representative genus was Desmodesmus An, Friedl \& Hegewald, with ten taxa. Chlorococcum Meneghini, nom. cons., Coelastrum Nägeli in Kützing and Sorastrum Kützing were the genera that least contributed toward the biodiversity, with only one taxon each.
\end{abstract}

Key words: Chlorococcales, Paraná State, river, taxonomy

RESUMO - (Chlorococcales planctônicas do Rio São João, Parque Nacional do Iguaçu, Paraná, Brasil). O trabalho objetivou o levantamento taxonômico das espécies algais pertencentes à ordem Chlorococcales (Chlorophyceae) do Rio São João, Parque Nacional do Iguaçu, Foz do Iguaçu, Paraná, Brasil. As amostras foram coletadas no período de junho de 2008 a maio de 2009 em três estações de amostragem ao longo do leito do rio. O material fitoplanctônico obtido com rede de plâncton com abertura de malha de $25 \mu \mathrm{m}$ foi imediatamente fixado em solução de Transeau. A análise qualitativa das amostras possibilitou a identificação de 28 táxons distribuídos nas famílias: Hydrodictyaceae, Oocystaceae e Scenedesmaceae. O gênero mais representativo foi Desmodesmus An, Friedl \& Hegewald com dez táxons do total. Chlorococcum Meneghini, nom. cons., Coelastrum Nägeli in Kützing e Sorastrum Kützing foram os gêneros que menos contribuíram para a biodiversidade, com apenas um táxon cada.

Palavras-chave: Chlorococcales, Estado do Paraná, rio, taxonomia

\section{Introdução}

No Brasil alguns trabalhos contribuíram para o conhecimento da taxonomia de Chlorococcales, como por exemplo, Leite (1974) que identificou, descreveu e ilustrou 60 táxons provenientes de coletas no Parque Estadual das Fontes do Ipiranga em São Paulo. Posteriormente Sant'Anna \& Martins (1982) registraram 48 táxons nos Lagos Cristalino e São Sebastião no Estado do Amazonas. Sant'Anna (1984) identificou 118 táxons para o Estado de São Paulo e Rosa \& Miranda-Kiesslich (1988) 11 táxons para o Rio Grande do Sul. Nogueira (1991) realizou o inventário das Chlorococcales de Rio de Janeiro e arredores registrando 122 táxons, e mais recentemente Nogueira \& Oliveira (2009) registraram 46 táxons em lagos artificiais no estado de Goiás.

No Estado do Paraná o primeiro registro de Chlorococcales encontra-se em Andrade \& Rachou (1954), os autores ao analisarem o plâncton de criadores de mosquitos documentaram 87 táxons de microalgas, nove pertencentes às Chlorococcales. $\mathrm{Na}$ sequência segue os registros das Chlorococcales apenas em nível genérico: Moreira Filho \& Moreira (1972), Cecy et al. (1976); Lozovei \& Luz (1976), Moreira Filho et al. (1976), Lozovei \& Hohmann (1977), Stankiewicz (1980) e Stankiewicz et al. (1981).

1. Programa de Pós-Graduação em Recursos Pesqueiros e Engenharia de Pesca, Universidade Estadual do Oeste do Paraná

2. Instituto de Botânica, Seção de Ecologia, Caixa Postal 3005, 01061-970 São Paulo, SP, Brasil

3. Universidade Estadual do Oeste do Paraná, Cascavel, Rua da Faculdade 645, Bloco C, Jardim La Salle, 85903-000 Toledo, Paraná, Brasil

4. Autor para correspondência: ncbueno@unioeste.br 
Para ambientes lênticos do Estado do Paraná, Picelli-Vicentim (1987) realizou o levantamento pioneiro das Chlorococcales em nível específico. A autora registrou 61 táxons para o lago do Parque Regional do Iguaçu, Curitiba. Rodrigues \& Train (1993) documentaram 30 táxons para o lago do Parque Alfredo Nyffler, Maringá. Picelli-Vicentim et al. (2001) documentaram 32 táxons para a Represa do Rio Passaúna e Moresco \& Bueno (2007) registraram 21 táxons da família Scenedesmaceae para o Lago Municipal de Cascavel.

Para ambientes lóticos do Estado do Paraná, Oliveira et al. (1994) registraram a presença de apenas três táxons de Chlorococcales no Rio Paraná e Bittencourt-Oliveira (1997) documentou a ocorrência de 18 táxons de Chlorococcales para o Rio Tibagi.

Considerando que estudos relacionados à comunidade fitoplanctônica de ambientes lóticos ainda são escassos, o presente trabalho apresenta o inventário florístico das Chlorococcales do Rio São João, Parque Nacional do Iguaçu, contribuindo assim com estudos da biodiversidade ficológica do Estado do Paraná.

\section{Material e métodos}

O Rio São João (25³7'27’S e 54²8'03”W) está inserido na bacia do Rio Iguaçu, com área total de cerca de $79,10 \mathrm{~km}^{2}$, dos quais $28,09 \mathrm{~km}^{2}$ estão localizados dentro do Parque Nacional do Iguaçu (PNI). Três estações de amostragem no eixo longitudinal foram selecionadas dentro do trecho do PNI, as quais seguem: Estação 1, 25 $37^{\circ} 14^{\prime \prime}$ S e

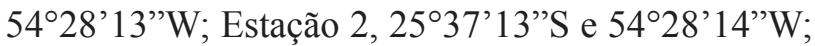
Estação 3, 2537'14"S e 54²8'33'” (figura 1).

As amostras foram coletadas mensalmente, num total de 36, no período de junho de 2008 a maio de 2009. O material biológico foi obtido com rede de plâncton com malha de $25 \mu \mathrm{m}$ de abertura e imediatamente preservado em solução Transeau, na proporção 1:1 (Bicudo \& Menezes 2006). Para as análises qualitativas foram preparadas lâminas temporárias, em média 10 lâminas por amostra. A análise das lâminas e as ilustrações botânicas foram realizadas com microscópio binocular acoplado com câmara clara em aumentos de 400 e $1.000 \times$. O sistema de classificação adotado em nível de família foi Bicudo \& Menezes 2006, sendo que para a identificação dos táxons seguiu-se Komárek \& Fott (1983), Comas (1996) e Hegewald (2000). As amostras encontram-se depositadas no Herbário da
Universidade Estadual do Oeste do Paraná (UNOP), Campus Cascavel.

Para a descrição dos táxons encontrados as seguintes abreviaturas referentes aos limites métricos (em $\mu \mathrm{m}$ ) foram utilizadas: $\mathrm{C}=$ comprimento celular; $\mathrm{Ccp}=$ comprimento celular com pedúnculo; $\mathrm{Cp}=$ comprimento dos processos; $\mathrm{D}=$ diâmetro celular; $\mathrm{Dc}=$ diâmetro do cenóbio; $\mathrm{E}=$ comprimento dos espinhos; $\mathrm{Ep}=$ comprimento das espínulas; $\mathrm{L}=$ largura celular.

\section{Resultados e Discussão}

A ordem Chlorococcales no Rio São João esteve representada por 28 táxons distribuídos nas famílias Hydrodictyaceae, Oocystaceae e Scenedesmaceae. A distribuição dos táxons ocorreu nos seguintes gêneros: Ankistrodesmus (6), Chlorella (1), Coelastrum (1), Desmodesmus (10), Monoraphidium (2), Pediastrum (2), Scenedesmus (5), Sorastrum (1).

Chlorococcales

HYDRODICTYACEAE

Pediastrum Meyen

Células organizadas em colônias planas, formando cenóbios de quatro até 128 células, sempre em múltiplos de dois. Células com formato poliédrico, tendo as periféricas um, dois, três ou quatro lobos ou processos menos proeminentes. Podem estar fortemente unidas ou deixar espaços entre elas, formando cenóbios clatrados. As células internas e externas diferem morfologicamente. Parede celular lisa ou ornamentada por grânulos, verrugas ou cristas. Cloroplasto único e parietal, preenchendo o formato celular. Um único pirenóide presente em cada plastídio. Pediastrum possui uma ampla distribuição geográfica, bem como ampla variedade morfológica (Komárek \& Fott 1986, Comas 1996, Bicudo \& Menezes 2006).

Chave artificial para identificação dos táxons de Pediastrum encontrados no Rio São João

1. Cenóbios arredondados com espaços intercelulares P. duplex var. duplex

1. Cenóbios quadráticos a arredondados sem espaços intercelulares P. tetras var. tetras

Pediastrum duplex Meyen var. duplex, Nova Acta Acad. Caesar. Leop. Carol. 14: 772, pl. 43, fig. 6-20. 1829. 

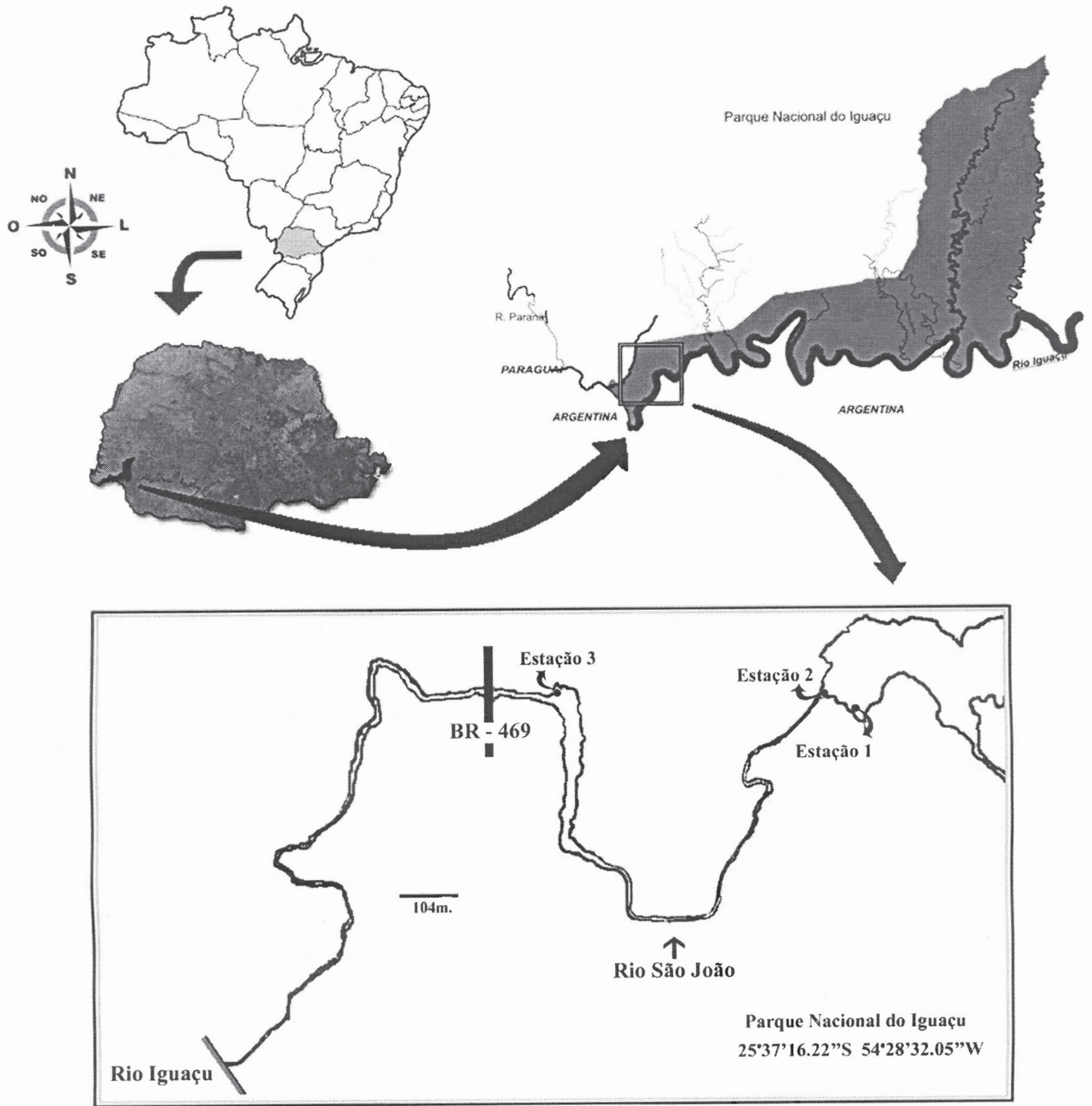

Figura 1. Localização do Rio São João, Parque Nacional do Iguaçu, Foz do Iguaçu, Paraná, Brasil. Figure 1. Location of the São João River, Iguaçu National Park, Foz do Iguaçu, Paraná, Brazil. 
Figura 2

Cenóbios arredondados, 8-16-32 células dispostas concentricamente, com espaços intercelulares, células em formato de $\mathrm{H}$, células externas poligonais apresentando margens retas ou côncavas, unidas pela base, com 2 processos cilíndricotruncados, curtos, células internas poligonais ou quase retas, parede celular lisa, cloroplasto parietal percorrendo todo o formato celular, 1 pirenóide. $\mathrm{C}=$ 14,7-15,2 $\mu \mathrm{m} ; \mathrm{L}=16,8-16,9 \mu \mathrm{m}$.

Material examinado: BRASIL. PARANÁ: Foz do Iguaçu, Parque Nacional do Iguaçu, Rio São João, 28-X-2008, J.C. Bortolini 11 (UNOP); idem, 28X-2008, J.C. Bortolini 12 (UNOP); idem, 28-XI2008, J.C. Bortolini 17 (UNOP); idem, 28-XI-2008, J.C. Bortolini 18 (UNOP); idem, 17-XII-2008, J.C. Bortolini 25 (UNOP); idem, 26-III-2009, J.C. Bortolini 40 (UNOP); idem, 26-III-2009, J.C. Bortolini 41 (UNOP); idem, 30-IV-2009, J.C. Bortolini 46 (UNOP); idem, 27-V-2009, J.C. Bortolini 55 (UNOP).

Pediastrum duplex var. duplex aqui registrado enquadra-se nos espécimes que apresentam processos curtos, uma vez que podem ser encontrados também indivíduos com processos mais longos, como aconteceu em Sant'Anna (1984) que observou nas populações analisadas indivíduos com processos longos, intermediários e raramente curtos. Este táxon pode ser confundido com cenóbios jovens de $P$. boryanum (Turpin) Meneghini var. boryanum, porém, este último não apresenta clatrações e seus processos são cônico-truncados e apresenta cloroplasto menor.

Pediastrum tetras (Ehrenberg) Ralfs var. tetras, Ann. Mag. Nat. Hist. 14: 469, pl. 2, fig. 4. $1845 \equiv$ Micrasterias tetras Ehrenberg, Infus., 155. 1838. Figuras 3-4

Cenóbios quadráticos a arredondados, com 4-8 células dispostas concentricamente, sem espaços intercelulares, células internas e externas poligonais, com incisão mediana profunda nas externas e mais estreita nas internas, sendo as externas formadas por 2 processos bifurcados, parede celular lisa, cloroplasto único, parietal, acompanhando o formato celular, 1 pirenóide. $\mathrm{C}=8,1-13,7 \mu \mathrm{m} ; \mathrm{L}=7,2-12,9 \mu \mathrm{m}$.

Material examinado: BRASIL. PARANÁ: Foz do Iguaçu, Parque Nacional do Iguaçu, Rio São João, 16-VI-2008, N.C. Bueno 1067 (UNOP); idem, 16VI-2008, N.C. Bueno 1068 (UNOP); idem, 28-X2008, J.C. Bortolini 10 (UNOP); idem, 28-X-2008, J.C. Bortolini 11 (UNOP).
Pediastrum tetras var. tetras compreende uma das espécies melhor caracterizadas morfologicamente dentro do seu gênero. Espécies como P. obtusum Lucks e $P$. longecornutum (Gutwinski) Comas assemelham-se a $P$. tetras, porém, tais espécies apresentam as células mais distantes uma das outras, ocasionando a formação de espaços intercelulares.

\section{Sorastrum Kützing}

Colônias globosas com 8-128 células radialmente dispostas, células com formatos piriformes, reniformes, ou piramidais, com prolongamento na fase interna, que é voltada para o centro da colônia, através de um pedicelo razoavelmente grosseiro até atingir o centro da colônia, a qual é formada por células poligonais, que formam a base destes pedicelos. $\mathrm{Na}$ fase externa, a qual é voltada para o exterior da colônia, podem existir um, dois ou até quatro espinhos. Possui cloroplastídio único, parietal e com um único pirenóide no centro (Bicudo \& Menezes 2006).

Sorastrum americanum (Bohlin) Schimidle var. americanum, Engler's Bot. Jb. 27: 230, pl. 1-3. 1900.

Figura 5

Cenóbios arredondados com 16 células dispostas radialmente, com formato piramidal e 2-4 processos afilados e longos, presença de um pedúnculo longo, delgado, unido pela base poligonal com a porção proximal mais afilada e porção distal alargada, margens retas ou côncavas, cloroplasto único, parietal, 1 pirenóide. $\mathrm{Ccp}=12,1-16,8 \mu \mathrm{m} ; \mathrm{L}=8,4-$ 10,5 $\mu \mathrm{m}$; Cp: 2,1-4,2 $\mu \mathrm{m}$.

Material examinado: BRASIL. PARANÁ: Foz do Iguaçu, Parque Nacional do Iguaçu, Rio São João, 16-VI-2008, N.C. Bueno 1068 (UNOP).

Sorastrum americanum var. americanum pode ser confundido com S. spinulosum Nägeli, entretanto, este último apresenta corpo central menos nítido, devido à superposição de algumas células, presença de pedúnculo e processos menores quando comparado com $S$. americanum. Segundo Nogueira (1991) a característica típica do gênero ainda é o arranjo radial das células que convergem de um corpo central nítido, esférico e oco.

\section{OOCYSTACEAE}

Ankistrodesmus Corda

Células organizadas em colônias, raramente solitárias, formando tufos ou feixes frouxos, 

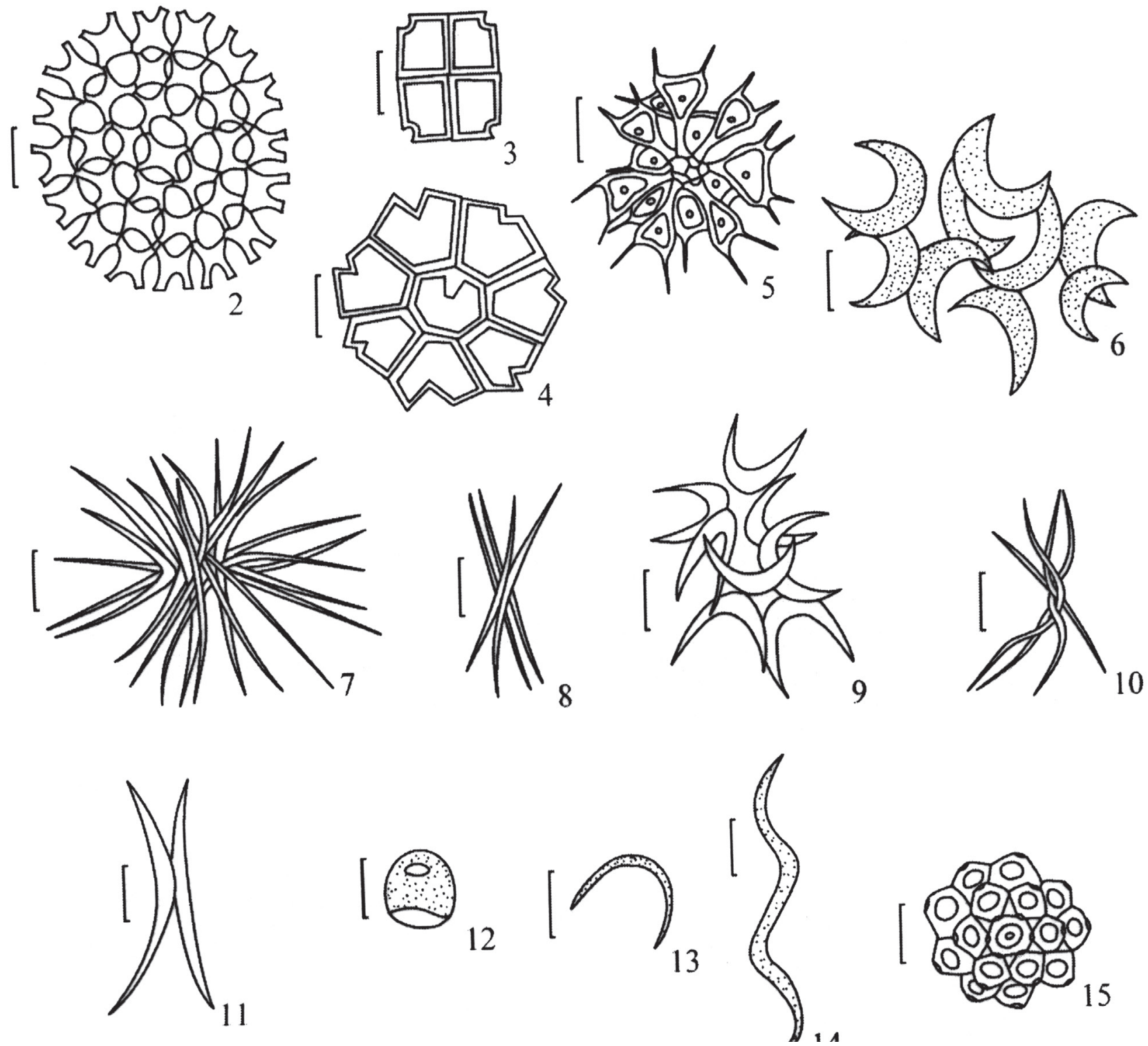

Figuras 2-15. 2. Pediastrum duplex var. duplex. 3-4. Pediastrum tetras var. tetras. 5. Sorastrum americanum var. americanum. 6. Ankistrodesmus bribaianus. 7. Ankistrodesmus densus. 8. Ankistrodesmus fusiformis. 9. Ankistrodesmus gracilis. 10. Ankistrodesmus spiralis. 11. Ankistrodesmus stipitatus. 12. Chlorella vulgaris. 13. Monoraphidium arcuatum. 14. Monoraphidium irregulare. 15. Coelastrum pulchrum var. pulchrum. Barras de escala $=10 \mu \mathrm{m}$, exceto figuras 5, 12, $13=25 \mu \mathrm{m}$.

Figures 2-15. 2. Pediastrum duplex var. duplex. 3-4. Pediastrum tetras var. tetras. 5. Sorastrum americanum var. americanum. 6. Ankistrodesmus bribaianus. 7. Ankistrodesmus densus. 8. Ankistrodesmus fusiformis. 9. Ankistrodesmus gracilis. 10. Ankistrodesmus spiralis. 11. Ankistrodesmus stipitatus. 12. Chlorella vulgaris. 13. Monoraphidium arcuatum. 14. Monoraphidium irregulare. 15. Coelastrum pulchrum var. pulchrum. Scale bars $=10 \mu \mathrm{m}$, except figures 5, 12, $13=25 \mu \mathrm{m}$. 
ordenadas paralelamente ou às vezes espiraladamente umas sobre as outras. Células com formato fusiforme, lunadas, mais largas que longas, ligeiramente retas, curvadas ou até sigmóides com os pólos afilados. Cloroplastos parietais, laminares, ocupando quase todo o espaço intercelular. Pirenóides podem ou não estar presentes, assim como podem variar de um a muitos. Parede celular lisa e incolor. Compreende um gênero cosmopolita podendo ser encontrado principalmente no plâncton (Comas 1996, Bicudo \& Menezes 2006).

Chave para identificação dos táxons de Ankistrodesmus encontrados no Rio São João

1. Células lunadas ou semicirculares

2. Células 3,5-3,8 vezes mais longas que largas, 15,7-17,4 $\mu \mathrm{m}$ compr., 4,1-4,9 $\mu \mathrm{m}$ larg A. bibraianus

2. Células 10-15 vezes mais longas que largas, 21-31,5 $\mu \mathrm{m}$ compr., $2,1 \mu \mathrm{m}$ larg A. gracilis

1. Células fusiformes, retas ou levemente arcuadas

3. Cenóbios com apenas 2 células A. stipitatus

3. Cenóbios com mais de 2 células

4. Cenóbios com células cruzadas umas sobre as outras A. fusiformis

4. Cenóbios com células torcidas umas sobre as outras

5. Cenóbios com no máximo 8 células torcidas umas sobre as outras A. spiralis

5. Cenóbios com no mínimo 16 células torcidas umas sobre as outras A. densus

Ankistrodesmus bibraianus (Reinsch) Koršikov, Protococcineae 302, fig. 265. 1953 ESelenastrum bibraianum Reinsch, Algenfl. Franken 64. 1867.

Figura 6

Cenóbios com 4 a 16 células lunadas ou semicirculares, com as margens ventrais fortemente convexas voltadas para o centro da colônia, afilando em direção ao ápice celular, cloroplasto parietal e único ocupando todo o espaço intercelular, pirenóide não observado. $\mathrm{C}=15,7-17,4 \mu \mathrm{m} ; \mathrm{L}=4,1-4,9 \mu \mathrm{m}$. Material examinado: BRASIL. PARANÁ: Foz do Iguaçu, Parque Nacional do Iguaçu, Rio São João, 30-IV-2009, J.C. Bortolini 47 (UNOP).

Ankistrodesmus bibraianus assemelha-se a $A$. gracilis (Reinsch) Koršikov devido ao formato celular e as margens fortemente voltadas para o centro do cenóbio. A. bibraianus, no entanto, apresenta número maior de células na colônia e a relação comprimento/ largura é inferior quando comparado com $A$. gracilis.

Ankistrodesmus densus Koršikov, Protococcineae 300, fig. 262. 1953.

Figura 7

Cenóbios fasciculados com 16 células densamente agrupadas, cilíndricas, fusiformes alongadas, levemente arcuadas, afiladas em direção ao ápice, torcidas uma sobre as outras ou superpostas, outras quase retas, 17-32 vezes mais longas que largas, cloroplastos parietais, pirenóides não observados. C $=25,9-28,3 \mu \mathrm{m} ; \mathrm{L}=0,8-1,6 \mu \mathrm{m}$.
Material examinado: BRASIL. PARANÁ: Foz do Iguaçu, Parque Nacional do Iguaçu, Rio São João, 16-VI-2008, N.C. Bueno 1068 (UNOP).

Ankistrodesmus densus difere das demais espécies pela formação de densos fascículos. Assemelha-se morfologicamente a A. spiralis (Turner) Lemmermann. Difere, no entanto, por apresentar no mínimo 16 células no cenóbio, enquanto em $A$. spiralis o número de células varia de 4 a 8 . De acordo com Nogueira (1991) A. densus também se assemelha a $A$. bernardii Komárek quanto ao arranjo das colônias, porém, as duas espécies diferem pela forma e dimensão das células.

Ankistrodesmus fusiformis Corda sensu Koršikov, Protococcineae: 300, fig. 263. 1953. Figura 8

Cenóbios estrelados formados por 4 células, cruciadas, fusiformes, retas a arcuadas, afiladas em direção ao ápice, cruzando umas sobre as outras, pólos pontiagudos, 15-21 vezes mais longas que largas, cloroplasto único e parietal, laminado, sem pirenóide. $\mathrm{C}=34,8-36,4 \mu \mathrm{m} ; \mathrm{L}=1,6-2,4 \mu \mathrm{m}$.

Material examinado: BRASIL. PARANÁ: Foz do Iguaçu, Parque Nacional do Iguaçu, Rio São João, 16-VI-2008, N.C. Bueno 1067 (UNOP); idem, 16VI-2008, N.C. Bueno 1068 (UNOP); idem, 28-VII2008, N.C. Bueno 1078 (UNOP); idem, 28-XI-2008, J.C. Bortolini 17 (UNOP); idem, 27-V-2009, J.C. Bortolini 56 (UNOP). 
Ankistrodesmus fusiformis difere de A. spiralis pela disposição das células, que são cruzadas e não torcidas, como acontece em $A$. spiralis. Suas células também podem ser confundidas com Monoraphidium griffithii (Berkeley) Komárková-Legnerová quando isoladas do cenóbio, uma vez que são células fusiformes e apresentam medidas celulares muito próximas. Segundo Komárek \& Fott (1983) este táxon é bem distinto, não apresentando variação em seus caracteres.

Ankistrodesmus gracilis (Reinsch) Koršikov, Protococcineae 305. 1953 三 Selenastrum gracile Reinsch, Algenfl. Franken 64. 1867. Figura 9

Cenóbios com 4-8 células lunadas, com a margem ventral convexa voltada para o centro da colônia, ápices afilados, cloroplasto único, parietal, pirenóide não observado. $\mathrm{C}=21-31,5 \mu \mathrm{m} ; \mathrm{L}=2,1 \mu \mathrm{m}$. Material examinado: BRASIL. PARANÁ: Foz do Iguaçu, Parque Nacional do Iguaçu, Rio São João, 30-IV-2009, J.C. Bortolini 47 (UNOP).

Ankistrodesmus gracilis assemelha-se a A. bibraianus, diferindo por apresentar relação comprimento/largura superior. Em Comas (1996) A. gracilis é enquadrado como sinônimo de Selenastrum gracilis Reinsch, e que segundo o autor apresentaria uma distribuição cosmopolita, principalmente em ambientes eutrofizados.

Ankistrodesmus spiralis (Turner) Lemmermann, Arch. Hydrobiol. U. Planktonk. 4: 176. 1908. Figura 10

Cenóbios com 1 fascículo, células fusiformes, dispostas em formato de hélice, com 4-8 células, ápices afilados, torcidas uma sobre as outras, unidas entre si pela região mediana, cloroplasto único, parietal, sem pirenóides, parede celular finamente pontuada. $\mathrm{C}=33,6-35,7 \mu \mathrm{m} ; \mathrm{L}=1,8-2,1 \mu \mathrm{m}$.

Material examinado: BRASIL. PARANÁ: Foz do Iguaçu, Parque Nacional do Iguaçu, Rio São João, 28-XI-2008, J.C. Bortolini 16 (UNOP).

Ankistrodesmus spiralis é morfologicamente semelhante a $A$. densus, porém, apresenta de 4 a 8 células no cenóbio e maior torção das células. $A$. densus apresenta cenóbio com 16 ou mais células, menor torção das células do cenóbio e medidas celulares pouco menores.

Ankistrodesmus stipitatus (Chodat) KomárkováLegnerová in Fott (ed.), Stud. Phyc. 87. 1969.
Figura 11

Cenóbios com apenas duas células, fusiformes, uma delas mais arcuada, outra mais reta, ápices afilados, unidas uma a outra pela região central das células, cloroplasto único e parietal, sem pirenóides, parede celular lisa. $\mathrm{C}=31,9-39 \mu \mathrm{m}, \mathrm{L}=1,6-2 \mu \mathrm{m}$. Material examinado: BRASIL. PARANÁ: Foz do Iguaçu, Parque Nacional do Iguaçu, Rio São João, 16-VI-2008, N.C. Bueno 1068 (UNOP).

Ankistrodesmus stipitatus assemelha-se a $A$. falcatus (Corda) Ralfs, entretanto, este último apresenta cenóbios com 4 ou mais células e menor relação comprimento/largura.

Chlorococcum Meneghini, nom. cons.

Células em geral unicelulares e de vida livre, raro formando agrupamentos temporários destituídos de forma definida que podem ser envoltos por mucilagem muito delgada, quase imperceptível. Células esféricas, parede celular lisa, cloroplasto parietal em forma de copo ou de uma esfera que preenche internamente toda a célula, possuindo um ou vários pirenóides. Inclui diversas espécies de quase todo o mundo, sendo também conhecido de amostragens realizadas em solos e ambientes subaéreos (Comas 1996, Bicudo \& Menezes 2006).

Chlorococcum pinguideum Arce \& Bold, Amer. J. Bot. 45: 498, pl. 93, fig. 32-41. 1958.

Figura 12

Células isoladas, de formato esférico, às vezes elipsóides ou ovaladas, parede celular lisa, cloroplasto único e parietal, ocupando quase todo o espaço celular, com um pirenóide bem evidente. $\mathrm{D}=$ 28,6-31,5 $\mu \mathrm{m}$.

Material examinado: BRASIL. PARANÁ: Foz do Iguaçu, Parque Nacional do Iguaçu, Rio São João, 28-XI-2008, J.C. Bortolini 16 (UNOP); idem, 22-I2009, J.C. Bortolini 28 (UNOP).

Chlorococcum pinguideum foi registrado por Comas (1996) em Cuba em solo úmido e em plantações de cana de açúcar, afirmando a sua distribuição também em outros ambientes. Komárek \& Fott (1983) afirmam a proximidade dos gêneros Chlorococcum e Chlorella Beijerinck, os quais diferem basicamente pela formação de autósporos em Chlorella e de zoósporos e aplanósporos em Chlorococcum.

Monoraphidium Komárkova-Legnerová Células solitárias, fusiformes, retas, curvadas, 
arqueadas ou até sigmóides, às vezes cilíndricas, muito mais longas que largas. Pólos celulares afilados gradualmente, agudos ou mais ou menos arredondados. Cloroplasto parietal, em forma de lâmina revestindo toda a parede celular, afastando-se dos pólos e da região mediana da célula quando em idade avançada. No entanto, ainda na célula jovem ocorre uma reentrância lateral mediana do plastídio, local onde se aloja o núcleo celular. Habitam ambientes oligo a mesotróficos e é considerado um gênero cosmopolita (Bicudo \& Menezes 2006).

Chave para identificação dos táxons de Monoraphidium encontrados no Rio São João

1. Células isoladas, arqueadas em semicírculo, ligeiramente sigmóides M. arcuatum

1. Células isoladas, fusiformes, curvas, sigmóides a espiraladas M. irregulare

Monoraphidium arcuatum (Koršikov) Hindák, Algol. Stud. 1:25, fig.9-10.1970 =Ankistrodesmus arcuatus Koršikov, Protococcineae 296, fig. 257. 1953.

Figura 13

Células isoladas, delgadas, arqueadas em semicírculo, às vezes ligeiramente sigmóides, ápices atenuados gradualmente, pólos pontiagudos, afilados, cloroplasto parietal, sem pirenóides. $\mathrm{C}=44,1-53,2$ $\mu \mathrm{m} ; \mathrm{L}=2,1-4,2 \mu \mathrm{m}$.

Material examinado: BRASIL. PARANÁ: Foz do Iguaçu, Parque Nacional do Iguaçu, Rio São João, 26-III-2009, J.C. Bortolini 42 (UNOP); idem, 30-IV2009, J.C. Bortolini 46 (UNOP); idem, 27-V-2009, J.C. Bortolini 55 (UNOP); idem, 27-V-2009, J.C. Bortolini 57 (UNOP).

Monoraphidium arcuatum tem como principal característica o formato de arco de sua célula, o que facilitanasuaidentificação.Comas(1996)documentou o táxon para Cuba, sendo que sua distribuição foi caracterizada como cosmopolita, sendo identificado no plâncton e no perifiton de ambientes eutrofizados. Komárek \& Fott (1983) também documentaram o táxon no plâncton e metafíton, atribuindo a mesma distribuição cosmopolita ao táxon.

Monoraphidium irregulare (G.M. Smith) Komarkóvá-Legnerová, J. Stud. Phycol. 106-107, pl. 19.

$1969 \equiv$ Dactylococcopsis irregularis G.M. Smith Ark. Bot. 17: 6. 1922.
Figura 14

Células isoladas, delgadas, fusiformes, curvas, sigmóides a espiraladas, ápices afilados, cloroplasto parietal, ocupando quase toda a célula, sem pirenóides. $\mathrm{C}=97-105 \mu \mathrm{m} ; \mathrm{L}=4,2-4,8 \mu \mathrm{m}$.

Material examinado: BRASIL. PARANÁ: Foz do Iguaçu, Parque Nacional do Iguaçu, Rio São João, 28-X-2008, J.C. Bortolini 10 (UNOP).

Monoraphidium irregulare assemelha-se a $M$. contortum (Thuret). Difere, porém, por apresentar maior comprimento celular, menor diâmetro e maior número de voltas das células no cenóbio. O táxon apresenta distribuição cosmopolita, principalmente em ambientes oligo a mesotróficos, segundo Comas (1996).

\section{SCENEDESMACEAE \\ Coelastrum Nägeli}

Colônias com formato de esfera oca, com $4,8,16,32$ ou raro 64 células. Indivíduos de vida livre, variando seu formato desde esféricas até poligonais, com um número de apêndices mais ou menos longos unindo as células entre si. Possui um único cloroplastídio com formato poculiforme e um pirenóide central. Coelastrum habita ambientes aquáticos continentais desde meso a eutróficos, e pode ser considerado um gênero cosmopolita (Bicudo $\&$ Menezes 2006).

Coelastrum pulchrum Schmidle var. pulchrum, Ber. Deutsch. Bot. Ges. 10(4): 206, pl. 11, fig. 1-2. 1892.

Figura 15

Cenóbios esféricos com 8-16 células, espaços intercelulares presentes, células ovaladas, com projeções cônico-truncadas, 5-6 processos unindose cada um a uma célula vizinha, cloroplasto único, parietal, com um pirenóide. $\mathrm{Dc}=29-32,3 \mu \mathrm{m} ; \mathrm{D}=$ 6,6-7,4 $\mu \mathrm{m}$.

Material examinado: BRASIL. PARANÁ: Foz do Iguaçu, Parque Nacional do Iguaçu, Rio São João, 30-IV-2009, J.C. Bortolini 47 (UNOP).

Coelastrum pulchrum var. pulchrum tem como principal característica o formato de suas células, com projeções cônico-truncadas e a presença de cinco a seis processos. Segundo Comas (1996) os cenóbios de C. pulchrum var. pulchrum podem apresentar de 8 a 32 células e estarem presentes em ambientes oligo a mesotróficos.

Desmodesmus An, Friedl \& Hegewald 
Cenóbios planos formados por 2 a 16 células dispostas lado a lado, com os eixos mais longos paralelos entre si. As células possuem formato elipsóide ou ovóide, podendo ser iguais entre si ou as externas com um formato e as internas com outro. Parede celular é ornamentada com pequeninas verrugas, com um retículo ou com uma crista mediana. Ocorrem espinhos curtos ou longos nos pólos das células externas e em um ou ambos os pólos das células internas. Cloroplasto único, parietal, preenchendo todo o espaço intercelular com um pirenóide central. $\mathrm{O}$ gênero é originário de Scenedesmus Meyen 1829, no entanto, este não possui espinhos. Pode ser encontrado em diversos ambientes, mas principalmente em ambientes eutrofizados (Bicudo \& Menezes 2006).

Chave para identificação dos táxons de Desmodesmus encontrados no Rio São João

1. Células com apenas espinhos curtos

2. Células externas com espinhos diminutos na margem semelhantes a um pente

3. Células com a presença de costelas

D. brasiliensis

3. Células sem a presença de costelas

D. serratus

2. Células externas sem espinhos diminutos na margem semelhantes a um pente

4. Células dispostas alternadamente D. denticulatus var. denticulatus

4. Células dispostas linearmente D. denticulatus var. linearis

1. Células com espinhos longos e curtos

5. Células ornamentadas com espinhos longos e curtos

D. abundans

5. Células ornamentadas apenas com espinhos longos

6. Espinhos longos em apenas um dos ápices das células marginais

6. Espinhos longos nos dois ápices das células marginais

7. Presença de costelas na parede celular D. armatus var. bicaudatus

7. Ausência de costelas na parede celular

8. Células oblongas a trapezóides

D. communis

8. Células com outros formatos

9. Presença de uma protuberância na região central da célula marginal

9. Ausência de uma protuberância na região central da célula marginal

D. protuberans

D. opoliensis var. mononensis

Desmodesmus abundans (Kirchner) Chodat, Arch. Hydrobiol. Suppl. 131 (Algol. Stud. 96): 1. 2000 $\equiv$ Scenedesmus caudatus Corda f. abundans Kirchner in Cohn, Kryptogamen-Flora von Schlesien 2: 98. 1878.

Figuras 16-17

Cenóbios compostos por 4 células dispostas linearmente, elípticas a oblongas, pólos arredondados, células internas com 1 espinho curto em cada margem, ou alternando entre um ápice e outro, células externas com 1 espinho longo em cada ápice celular e 1 espinho menor na sua margem externa, cloroplasto axial, 1 pirenóide. $\mathrm{C}=8,1-9,7$ $\mu \mathrm{m} ; \mathrm{L}=1,6-2,4 \mu \mathrm{m} ; \mathrm{E}=0,8-6,4 \mu \mathrm{m}$.

Material examinado: BRASIL. PARANÁ: Foz do Iguaçu, Parque Nacional do Iguaçu, Rio São João, 16-VI-2008, N.C. Bueno 1067 (UNOP); idem, 16VI-2008, N.C. Bueno 1068 (UNOP); idem, 28-VIII2008, N.C. Bueno 1081 (UNOP).
Desmodesmus abundans é facilmente confundido com D. spinosus (R. Chodat) Hegewald, no entanto, a diferença entre as duas espécies reside no fato de $D$. abundans possuir dois espinhos de tamanhos desiguais nas margens externas das células. Os espinhos também podem ocorrer isolados ou, mais raramente, em número de três. Em D. spinosus os espinhos marginais são praticamente do mesmo tamanho, são em número muito maior e distribuemse em toda a parede celular de todo cenóbio.

Desmodesmus armatus (Chodat) Hegewald var. armatus, Arch. Hydrobiol. Suppl. 131 (Algol. Stud. 96): 2. $2000 \equiv$ Scenedesmus hystrix var. armatus, Alg. Vert. Suisse: 215, fig. 140. 1920. Figura 18

Cenóbios compostos por 2-4 células dispostas linearmente, cilíndricas a elipsóide, células externas levemente côncavas, células internas com 


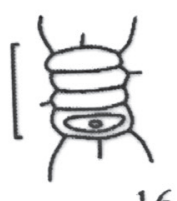

16

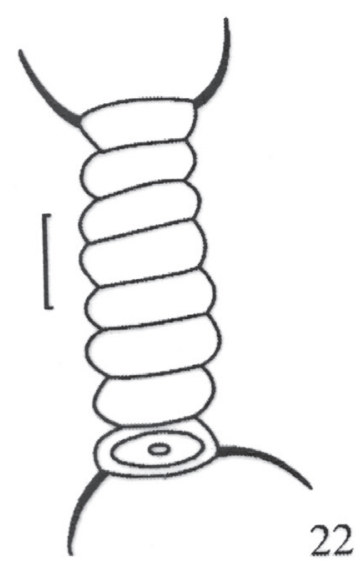

22

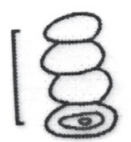

28

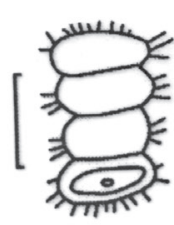

27

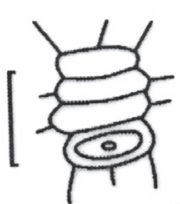

17
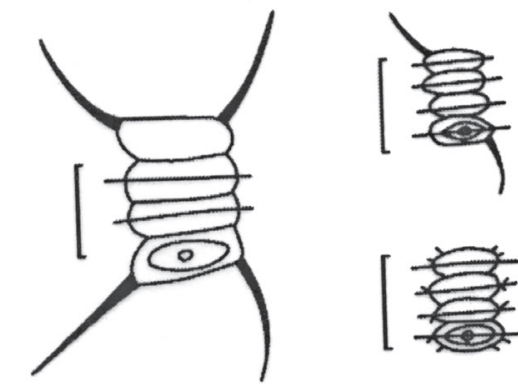

19

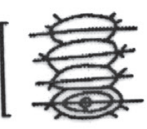

18

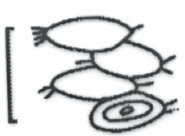

23

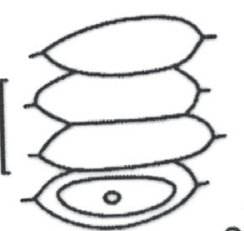

24
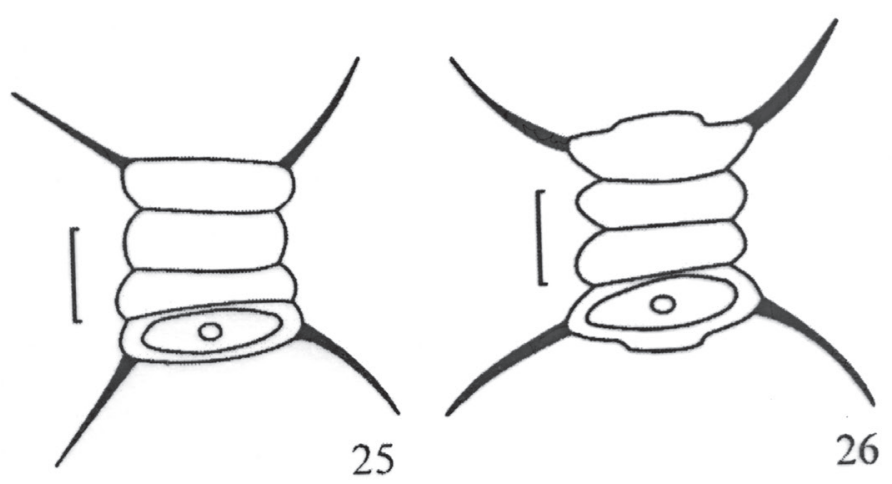

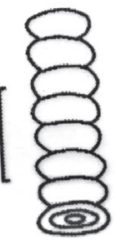

29
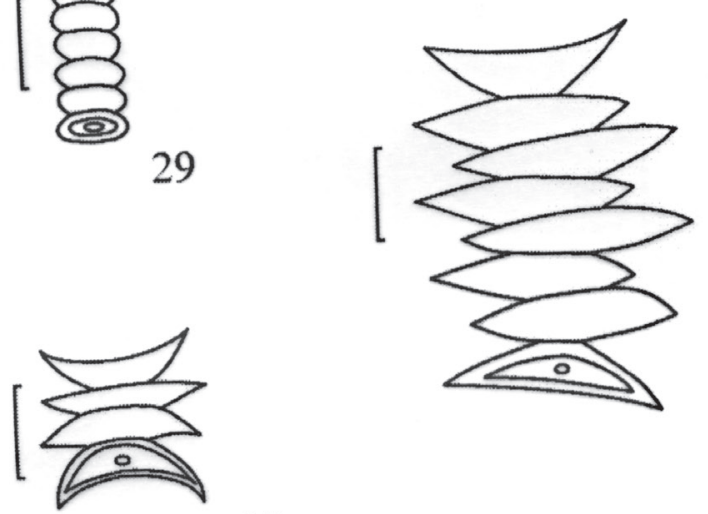

31
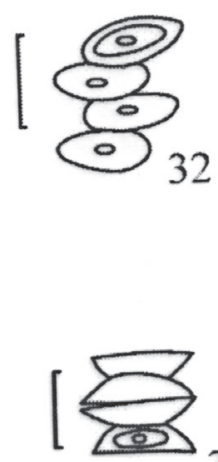

Figuras 16-33. Espécies de Hydrodictyaceae, Oocystaceae e Scenedesmaceae do Rio São João. 16-17. Desmodesmus abundans. 18. Desmodesmus armatus var. armatus. 19. Desmodesmus armatus var. bicaudatus. 20. Desmodesmus brasiliensis. 21-22. Desmodesmus communis. 23. Desmodesmus denticulatus var. denticulatus. 24. Desmodesmus denticulatus var. linearis. 25. Desmodesmus opoliensis var. mononensis. 26. Desmodesmus protuberans. 27. Desmodesmus serratus. 28-29. Scenedesmus ecornis. 30-31. Scenedesmus obliquus var. dimorphus. 32. Scenedesmus obtusus. 33. Scenedesmus securiformis. Barras de escala $=10 \mu \mathrm{m}$.

Figures 16-33. Species of Hydrodictyaceae, Oocystaceae e Scenedesmaceae from the São João River. 16-17. Desmodesmus abundans. 18. Desmodesmus armatus var. armatus. 19. Desmodesmus armatus var. bicaudatus. 20. Desmodesmus brasiliensis. 21-22. Desmodesmus communis. 23. Desmodesmus denticulatus var. denticulatus. 24. Desmodesmus denticulatus var. linearis. 25. Desmodesmus opoliensis var. mononensis. 26. Desmodesmus protuberans. 27. Desmodesmus serratus. 28-29. Scenedesmus ecornis. 30-31. Scenedesmus obliquus var. dimorphus. 32. Scenedesmus obtusus. 33. Scenedesmus securiformis. Scale bars $=10 \mu \mathrm{m}$. 
extremidades arredondadas a cônicas e com costelas, que às vezes pode aparecer nas externas, as costelas podem estender-se por toda a célula ou serem interrompidas, células externas com um espinho longo em cada ápice, cloroplasto axial, 1 pirenóide. $\mathrm{C}=8,2-12,1 \mu \mathrm{m} ; \mathrm{L}=2,4-4,8 \mu \mathrm{m} ; \mathrm{E}=9,7-12,3 \mu \mathrm{m}$. Material examinado: BRASIL. PARANÁ: Foz do Iguaçu, Parque Nacional do Iguaçu, Rio São João, 28-VIII-2008, N.C. Bueno 1078 (UNOP); idem, 25-IX-2008, J.C. Bortolini 3 (UNOP); idem, 28-X2008, J.C. Bortolini 10 (UNOP); idem, 28-X-2008, J.C. Bortolini 11 (UNOP); idem, 28-XI-2008, J.C. Bortolini 18 (UNOP); idem, 22-I-2008, J.C. Bortolini 30 (UNOP); idem, 30-IV-2009, J.C. Bortolini 47 (UNOP); idem, 30-IV-2009, J.C. Bortolini 48 (UNOP); idem, 27-V-2009, J.C. Bortolini 56 (UNOP).

Desmodesmus armatus é uma espécie relativamente comum nas amostras analisadas, porém, não tão fácil de ser identificada. É morfologicamente muito parecida com $D$. communis (Hegewald) Hegewald, da qual difere pela presença de costelas. D. armatus apresenta grande variação morfológica tanto na dimensão das células quanto no comprimento dos espinhos e na presença de costelas e que conforme Hindak (1990) e Hegewald (2000) compreende uma das espécies cujos caracteres diagnósticos apresentam ampla variabilidade.

Desmodesmus armatus (Guglielmetti) Hegewald var. bicaudatus, Arch. Hydrobiol. Suppl. 131 (Algol. Stud. 96): 4. $2000 \equiv$ Scenedesmus acutiformis Schröder var. bicaudatus Guglielmetti, N. Not. 21: 31. 1910.

Figura 19

Cenóbios compostos por 2-4 células dispostas linearmente, elípticas, pólos arredondados, células externas com apenas 1 espinho longo em um dos ápices disposto dispostos em direções opostas (diagonalmente), células internas com costelas que podem se estender aos dois extremos ou serem interrompidas na região mediana, cloroplasto parietal, 1 pirenóide. $\mathrm{C}=8,9-14,7 \mu \mathrm{m}$.; $\mathrm{L}=2,4-6,5$ $\mu \mathrm{m} ; \mathrm{E}=4,5-12,3 \mu \mathrm{m}$.

Material examinado: BRASIL. PARANÁ: Foz do Iguaçu, Parque Nacional do Iguaçu, Rio São João, 16-VI-2008, N.C. Bueno 1067 (UNOP); idem, 28VIII-2008, N.C. Bueno 1078 (UNOP); idem, 25IX-2008, J.C. Bortolini 1 (UNOP); idem, 28-XI2008, J.C. Bortolini 16 (UNOP); idem, 22-I-2009, J.C. Bortolini 29 (UNOP); idem, 26-III-2009,
J.C. Bortolini 40 (UNOP); idem, 27-V-2009, J.C. Bortolini 57 (UNOP).

Desmodesmus armatus var. bicaudatus difere da variedade típica da espécie pelo seu caráter bicaudado. Komárek \& Fott (1983) incluíram a espécie em Scenedesmus semipulcher Hortobágyi. Recentemente, foi feita a nova combinação $D$. armatus var. bicaudatus (Guglielmetti) Hegewald em Hegewald (2000). D. armatus var. bicaudatus está baseado em S. acutiformis Schröder var. bicaudatus Guglielmeti e é característico por apresentar somente dois espinhos localizados diagonalmente opostos em cada célula externa do cenóbio. O 'status' bicaudatus ocorre com frequência em outras espécies do gênero. Entretanto, Hegewald (2000) jamais considerou tal feição um bom caráter para separar variedades taxonômicas e, como tal, foi nominalmente transferido.

Desmodesmus brasiliensis (Bohlin) Hegewald, Arch. Hydrobiol. Suppl. 131 (Algol. Stud. 96): 7. $2000 \equiv$ Scenedesmus brasiliensis Bohlin, Bih. K. Svenska Vet.-Akad. Handl. 23 (Afd. III, 7): 22. 1897.

Figura 20

Cenóbios compostos por 4 células arranjadas linearmente, elípticas a oblongas, pólos arredondados, células externas e internas com 1-2(-3) espinhos pequenos que podem ou não aparecer em todas as células do cenóbio, costelas longitudinais medianas ao longo de toda extensão da célula ou fragmentada, células externas com ou sem rosetas, células externas geralmente com espinhos diminutos na margem, cloroplasto parietal, 1 pirenóide. $\mathrm{C}=9,7-15,3 \mu \mathrm{m}$.; $\mathrm{L}=2,4-4 \mu \mathrm{m}$.; $\mathrm{E}=0,8 \mu \mathrm{m}$.

Material examinado: BRASIL. PARANá: Foz do Iguaçu, Parque Nacional do Iguaçu, Rio São João, 16-VI-2008, N.C. Bueno 1067 (UNOP); idem, 16VI-2008, N.C. Bueno 1068 (UNOP); idem, 28VII-2008, N.C. Bueno 1077 (UNOP); idem, 28VII-2008, N.C. Bueno 1078 (UNOP); idem, 25-IX2008, J.C. Bortolini 1 (UNOP); idem, 25-IX-2008, J.C. Bortolini 2 (UNOP); idem, 25-IX-2008, J.C. Bortolini 3 (UNOP); idem, 28-X-2008, J.C. Bortolini 11 (UNOP); idem, 17-XII-2008, J.C. Bortolini 25 (UNOP); idem, 30-IV-2009, J.C. Bortolini 48 (UNOP).

Desmodesmus brasiliensis é uma espécie muito comum, cosmopolita e que apresenta considerável variação morfológica. As células elípticas a oblongas são um caráter estável na espécie, 
porém, os espinhos polares podem variar entre um e dois, raramente três, em todas as células do cenóbio, tanto nas externas quanto nas internas. As células externas geralmente possuem espinhos diminutos muito próximos da margem da célula que lembram um pente e uma membrana que envolve este pente. Esta estrutura é característica da espécie, no entanto, D. brasiliensis pode ser facilmente confundido com Scenedesmus serratus (Corda) Bohlin devido ao fato de também apresentar essa estrutura semelhante a um pente, porém, $S$. serratus apresenta espinhos marginais independentes mais separados um do outro do que em D. brasiliensis.

Desmodesmus communis (Hegewald) Hegewald, Arch. Hydrobiol. Suppl. 131 (Algol. Stud. 96): 8. $2000 \equiv$ Scenedesmus communis Hegewald, Arch. Hydrobiol./Suppl. 51 (Algol. Stud 19): 151. 1977. Figuras 21-22

Cenóbios compostos por 2-4-8 células dispostas linearmente, elípticas a oblongas, pólos arredondados, células externas com 1 espinho longo e curvado em cada pólo, células internas com extremidades arredondadas, sem espinhos e sem costelas, cloroplasto parietal, 1 pirenóide. $\mathrm{C}=6,4$ $18,8 \mu \mathrm{m} ; \mathrm{L}=4,5-7,9 \mu \mathrm{m} ; \mathrm{E}=6,4-22,1 \mu \mathrm{m}$.

Material examinado: BRASIL. PARANÁ: Foz do Iguaçu, Parque Nacional do Iguaçu, Rio São João, 16-VI-2008, N.C. Bueno 1067 (UNOP); idem, 16-VI2008, N.C. Bueno 1068 (UNOP); idem, 28-VII-2008, N.C. Bueno 1078 (UNOP); idem, 25-IX-2008, J.C. Bortolini 2 (UNOP); idem, 25-IX-2008, J.C. Bortolini 3 (UNOP); idem; 28-XI-2008, J.C. Bortolini 16 (UNOP); idem, 22-I-2009, J.C. Bortolini 28 (UNOP); idem, 27-02-2009, J.C. Bortolini 34 (UNOP); idem, 26-III-2009, J.C. Bortolini 40 (UNOP); idem, 30-IV2009, J.C. Bortolini 46 (UNOP); idem, 30-IV-2009, J.C. Bortolini 47 (UNOP).

Desmodesmus communis é mundialmente conhecida e amplamente distribuída geograficamente sob a combinação Scenedesmus quadricauda (Turpin) Brébisson sensu Chodat (1913, 1926), a qual foi substituída por Hegewald (1977) por $S$. communis Hegewald e, posteriormente, por Hegewald (2000) por D. communis (Hegewald) Hegewald. Características bastante variáveis nesta espécie são as dimensões das células e dos espinhos. Hegewald (2000) propôs a nova combinação de $D$. communis e nela incluiu a maior parte das variedades taxonômicas de $S$. quadricauda, onde permanece até os dias atuais sem qualquer outra mudança.
Desmodesmus denticulatus (Lagerheim) An, Friedl \& Hegewald var. denticulatus, Arch. Hydrobiol. Suppl. 131 (Algol. Stud. 96): 9. 2000 $\equiv$ Scenedesmus denticulatus Lagerheim Öfvers. K. [Svenska] Vet.-Akad. Förh. 39: 61. 1882. Figura 23

Cenóbios compostos por 4 células, dispostas de forma alternada, ovaladas a oblongas, assimétricas, células externas e internas com 1-3 espinhos pequenos nos pólos celulares, parede celular lisa, cloroplasto parietal, pirenóides não observados. $\mathrm{C}=21-21,5 \mu \mathrm{m}$; $\mathrm{L}=10,5-11,2 \mu \mathrm{m} ; \mathrm{E}=2,1-4,2 \mu \mathrm{m}$.

Material examinado: BRASIL. PARANÁ: Foz do Iguaçu, Parque Nacional do Iguaçu, Rio São João, 16-VI-2008, N.C. Bueno 1067 (UNOP); idem, 22-I2009, J.C. Bortolini 30 (UNOP); idem, 30-IV-2009, J.C. Bortolini 48 (UNOP).

Desmodesmus denticulatus é uma espécie bem delimitada e de fácil identificação taxonômica. Segundo Comas (1996) existem características nesta espécie que são bem marcantes, a saber: as quatro células alternadas são todas iguais, com um a quatro dentículos orientados paralelamente entre si ou ligeiramente inclinados em relação ao cenóbio. Sant'Anna (1984) mencionou ter observado indivíduos do tipo denticulatus ao lado de outros do tipo smithii, no entanto, a única diferença entre esses dois tipos é a presença ou ausência de uma angulosidade na região de contato entre as células. A referida autora ainda mencionou que tais populações são provavelmente de representantes da mesma espécie e que a diferença encontrada pode ser devido à ocorrência em locais diferentes, ou seja, aos fatores ambientais distintos de cada localidade.

Desmodesmus denticulatus (Hansgirg) Hegewald var. linearis, Arch. Hydrobiol. Suppl. 131 (Algol. Stud. 96): 10. 2000 EScenedesmus denticulatus var. linearis Hansgirg, Prodr. Alg. Böhmen 1: 268.1888.

Figura 24

Cenóbios compostos por 2-4 células, dispostas linearmente, ovaladas a oblongas, com 1-2 espinhos curtos nos pólos apicais, parede celular lisa, cloroplasto parietal, 1 pirenóide. $\mathrm{C}=18,2-19,4 \mu \mathrm{m}$; $\mathrm{L}=4,8-6,3 \mu \mathrm{m} ; \mathrm{E}=1,2-1,6 \mu \mathrm{m}$.

Material examinado: BRASIL. PARANÁ: Foz do Iguaçu, Parque Nacional do Iguaçu, Rio São João, 16-VI-2008, N.C. Bueno 1067 (UNOP).

Desmodesmus denticulatus var. linearis possui cenóbio linear formado por células oblongas a 
ovaladas ornadas com pequenos espinhos polares que podem aparecer tanto nas células internas quanto externas e são característicos desta espécie. D. denticulatus var. linearis possui originalmente, conforme Nogueira (1991), disposição linear das células no cenóbio, no que difere dos representantes da variedade típica da espécie, que possui arranjo alternado. Sant'Anna et al. (1989) e Ferragut et al. (2005) documentaram a presença de representantes de $D$. denticulatus var. linearis com dois dentículos em cada uma das duas células do cenobio. Nenhum espécime deste tipo foi encontrado nas populações ora estudadas. Consideramos os espécimes em Sant'Anna et al. (1989) e Ferragut et al. (2005) uma expressão do espectro da variação morfológica da referida atual var. linearis.

Desmodesmus opoliensis (P. Richter) Hegewald var. mononensis (R. Chodat) Hegewald, Arch. Hydrobiol. Suppl. 131 (Algol. Stud. 96): 15. 2000 三Scenedesmus opoliensis (P. Richter) Hegewald var. mononensis R. Chodat, Trans. Roy. Soc. S. Afr. 18: 31. 1929.

Figura 25

Cenóbios compostos por 4 células, dispostas linearmente, oblongas a elipsóides, células externas com pólos agudos quase truncados, com 1 espinho longo em cada pólo, espinhos situados excentricamente nos pólos celulares, células em contato em quase toda extensão, cloroplasto axial, 1 pirenóide. $\mathrm{C}=17,8-18,9 \mu \mathrm{m} ; \mathrm{L}=7,2-8,4 \mu \mathrm{m} ; \mathrm{E}=$ 14,7-15,3 $\mu \mathrm{m}$.

Material examinado: BRASIL. PARANÁ: Foz do Iguaçu, Parque Nacional do Iguaçu, Rio São João16VI-2008, N.C. Bueno 1068 (UNOP); idem, 27-V2009, J.C. Bortolini 55 (UNOP).

Segundo Hegewald \& Silva (1988), D. opoliensis var. mononensis difere da variedade típica da espécie pelas células que se tocam em quase toda sua extensão e pelos cenóbios organizados mais ou menos em linhas, além da presença de espinhos polares excêntricos.

Desmodesmus protuberans (Fritsch \& Rich) Hegewald, Arch. Hydrobiol. Suppl. 131 (Algol. Stud. 96): 16. $2000 \equiv$ Scenedesmus protuberans Fritsch \& Rich, Trans. Roy. Soc. S. Afr. 18: 31. 1929.

Figura 26

Cenóbios compostos por 2-4 células, dispostas linearmente, contorno oblongo, células externas com ápices cônico-arredondados com curvatura para fora do cenóbio e 1 espinho longo em cada ápice, presença de uma protuberância mais ou menos na região central da célula externa, cloroplasto axial, 1 pirenóide. $\mathrm{C}=19,6-22,1 \mu \mathrm{m} ; \mathrm{L}=5,6-6,4 \mu \mathrm{m} ; \mathrm{E}=$ 12,9-21,8 $\mu \mathrm{m}$.

Material examinado: BRASIL. PARANÁ: Foz do Iguaçu, Parque Nacional do Iguaçu, Rio São João, 28-VII-2008, N.C. Bueno 1078 (UNOP).

Conforme Comas (1996) esta espécie lembra muito quanto à sua morfologia, D. opoliensis, do qual difere, fundamentalmente, pelos seus pólos mais alargados, mais ou menos capitados e pelos espinhos localizados aproximadamente no centro dos pólos celulares. Sant'Anna (1984) aponta a morfologia dos pólos celulares como o único caráter diferencial entre D. opoliensis e D. protuberans.

Desmodesmus serratus (Corda) An, Friedl \& Hegewald, P1. Biol. (Stuttgart) 1: 427. 1999 $\equiv$ Arthrodesmus serratus Corda, Almanach de Carlsbad 9: 244, pl. 6, fig. 35. 1839.

Figura 27

Cenóbios compostos por 4 células dispostas linearmente, elípticas a elíptico-fusiformes, com pólos arredondados, células externas com espinhos pequenos nas margens, sem membrana, espinhos unidos formando uma estrutura parecida com um pente, células internas com 2-3 espinhos pequenos nos pólos, cloroplasto axial, 1 pirenóide. $\mathrm{C}=9,8-11,2$ $\mu \mathrm{m} ; \mathrm{L}=3,6-4,1 \mu \mathrm{m} ; \mathrm{E}=2,1 \mu \mathrm{m} ; \mathrm{Ep}=0,81 \mu \mathrm{m}$. Material examinado: BRASIL. PARANÁ: Foz do Iguaçu, Parque Nacional do Iguaçu, Rio São João, 25-IX-2008, J.C. Bortolini 3 (UNOP); idem, 22I-2009, J.C. Bortolini 28 (UNOP); idem, 26-III2009, J.C. Bortolini 40 (UNOP); idem, 30-IV-2009, J.C. Bortolini 47 (UNOP); idem, 27-V-2009, J.C. Bortolini 56 (UNOP).

Desmodesmus serratus apresenta células elípticas a ovaladas com pequenos espinhos em toda a margem das células externas. São espinhos espaçados e independentes. Além disso, existem dois ou três dentículos nos pólos de todas as células do cenóbio e uma costela longitudinal com pequenos dentes, que podem estar presentes ou não. $D$. serratus pode ser confundida com $D$. pseudodenticulatus (Hegewald) Hegewald, no entanto, a última espécie não apresenta costelas cortando a parede celular em nenhum momento. Mas, as duas espécies possuem espinhos independentes em toda extensão da margem externa da célula, porém, a forma da célula das duas 
espécies é bem distinta: $D$. serratus apresenta células elípticas a elíptico-fusiformes com pólos celulares arredondados e $D$. pseudodenticulatus possui células oblongas com pólos celulares arredondados ou, às vezes, truncados.

\section{Scenedesmus Meyen}

Colônia plana com 2 a 16 células, raro com 32, dispostas lado a lado, com seus eixos mais longos paralelos entre si. Podem estar dispostas exatamente uma célula ao lado da outra ou alternando, com uma célula mais para cima e a outra mais para baixo. Podem existir colônias formadas por duas séries de células superpostas, formando um disco. As células podem ser elipsóides, fusiformes, lunadas ou ovóides, sendo todas iguais no cenóbio ou as extremas de uma forma e as internas de outra. Parede celular lisa, às vezes ornada. Cloroplasto único por célula, parietal, preenchendo toda a célula. Ocorre um pirenóide central em cada célula. Compreende um gênero comum em ambientes aquáticos continentais, caracterizando-se como pioneiros na colonização destes ambientes (Bicudo \& Menezes 2006).

Chave artificial para identificação dos táxons de Scenedesmus encontrados no Rio São João

1. Células dispostas linear ou alternadamente

2. Células dispostas alternadamente ..... S. obtusus

2. Células dispostas linearmente ou às vezes alternadamente ....... S. obliquus var. dimorphus

1. Células dispostas somente linearmente

3. Células externas trapezóides e células internas mais arredondadas S. securiformis

3. Células externas e internas de formato oblongo S. ecornis

Scenedesmus ecornis (Ehrenberg ex Ralfs) Chodat, Z. Hidrol. 3: 170. 1926 EScenedesmus quadricauda var. ecornis Ehrenberg ex Ralfs, Ann. \& Mag., Nat. Hist. 15: 402. 1845.

Figuras 28-29

Cenóbios compostos por 4-8 células dispostas linearmente, bem juntas, formato oblongo, cloroplasto parietal, 1 pirenóide. $\mathrm{C}=7,2-9,7 \mu \mathrm{m} ; \mathrm{L}=2,4-4,1 \mu \mathrm{m}$. Material examinado: BRASIL. Paraná: Foz do Iguaçu, Parque Nacional do Iguaçu, Rio São João, 16-VI-2008, N.C. Bueno 1067 (UNOP); idem, 28VIII-2008, N.C. Bueno 1078 (UNOP); idem, 28-XI2008, J.C. Bortolini 16 (UNOP); idem, 17-XII-2008, J.C. Bortolini 25 (UNOP).
Segundo Comas (1996) S. ecornis possui parede celular completamente lisa, sem ornamentações ou espessamentos apicais. Os exemplares identificados em Ferragut et al. (2005) apresentam essas mesmas características, embora o espécime ilustrado apresente somente duas células no cenóbio. S. bijugus (Turpin) Kützing é um sinônimo heterotípico de S. ecornis.

Scenedesmus obliquus (Turpin) Kützing var. dimorphus (Turpin) Hansgirg, Archiv der nat. Landes. von Böh. 6: 116. $1888 \equiv$ Acnanthes dimorphus Turpin, Mém. Mus. Nat. d'Hist. Natur. 16: 313, p. 13, fig. 12.1828.

Figuras 30-31

Cenóbios formados por 4-8 células, dispostas linear ou alternadamente, fusiformes a ovalfusiformes, pólos agudos, células externas marcadamente côncavas podendo chegar a reta ou levemente convexa, células internas quase retas, cloroplasto único e parietal. $\mathrm{C}=16,2-25,1 \mu \mathrm{m} ; \mathrm{L}=$ 3,2-7,2 $\mu \mathrm{m}$.

Material examinado: BRASIL. PARANÁ: Foz do Iguaçu, Parque Nacional do Iguaçu, Rio São João, 16-VI-2008, N.C. Bueno 1067 (UNOP); idem, 28VIII-2008, N.C. Bueno 1078 (UNOP); idem, 25-IX2008, J.C. Bortolini 2 (UNOP); idem, 28-X-2008, J.C. Bortolini 12 (UNOP); idem, 17-XII-2008, J.C. Bortolini 25 (UNOP).

Scenedesmus obliquus pertence a um dos grupos de espécies de identificação mais complicada do subgênero Acutodesmus, devido à sua ampla variabilidade morfológica. Pode-se interpretar S. acuminatus (Lagerheim) Chodat sensu lato como claramente constituído por dois morfotipos, acuminatus e pectinatus, sem populações intermediárias, que taxonomicamente constutuiriam uma só espécie, S. obliquus que incluiria $S$. acutus Meyen e $S$. dimorphus Turpin, como fizeram autores como Hegewald $(1979,1989)$ e Holtmann \& Hegewald (1987) e não três espécies independentes, como fez Komárek \& Fott (1983). Aceitamos os critérios de Toledo \& Comas (1988) e Comas (1996), quando consideraram duas variedades taxonômicas: S. obliquus var. obliquus e $S$. obliquus var. dimorphus (incluindo $S$. acutus Meyen).

Scenedesmus obtusus Meyen, Verh. K. Leopold.Carol. Akad. Naturf., 14: 775, pl. 43, fig. 30-31. 1829.

Figura 32

Cenóbios compostos por 4-8 células, 
dispostas alternadamente em 1-2 séries, ovalcilíndricas, pólos arredondados, células externas convexas, podendo apresentar 1 leve concavidade mediana, células internas mais retas, cloroplasto parietal, 1 pirenóide. $\mathrm{C}=8,9-9,2 \mu \mathrm{m} ; \mathrm{L}=4,1-4,6 \mu \mathrm{m}$. Material examinado: BRASIL. PARANÁ: Foz do Iguaçu, Parque Nacional do Iguaçu, Rio São João, 16-VI-2008, N.C. Bueno 1068 (UNOP); idem, 25IX-2008, J.C. Bortolini 6 (UNOP); idem, 22-I-2009, J.C. Bortolini 28 (UNOP).

Scenedesmus obtusus pode ser facilmente confundido com $S$. ovalternus Chodat var. ovalternus e com $S$. arcuatus Lemmermann var. platydiscus G.M. Smith. Diferem, contudo, porque S. obtusus possui espaços intercelulares maiores do que os de $S$. arcuatus var. platydiscus e suas células são relativamente mais fusiformes, enquanto que as de S. arcuatus var. platydiscus apresentam margem um pouco côncava. S. obtusus é a espécie-tipo do gênero. Entre seus sinônimos mais conhecidos encontramse $S$. alternans Reinsch, S. graevenitzii (Bernard) Chodat e $S$. ovalternus Chodat. Este último nome é aplicado, de acordo com Hegewald \& Silva (1988), a uma espécie coletiva, portanto, considerada ilegítima.

Scenedesmus securiformis Playfair, Proc. Linn. Soc. N.S.W., 41: 835, pl. 57, fig. 16-17. 1917.

Figura 33

Cenóbios compostos por 4 células dispostas linearmente, células externas trapezóides, unidas ao longo de todo o seu comprimento, células internas mais arredondadas, afilando em direção ao ápice, cloroplasto único e parietal, 1 pirenóide. $\mathrm{C}=8,1-15,3$ $\mu \mathrm{m} ; \mathrm{L}=2,4-4,1 \mu \mathrm{m}$.

Material examinado: BRASIL. PARANÁ: Foz do Iguaçu, Parque Nacional do Iguaçu, Rio São João, 16-VI-2008, N.C. Bueno 1067 (UNOP); idem, 17XII-2008, J.C. Bortolini 25 (UNOP).

Scenedesmus securiformis tem como principal característica suas células externas de formato trapezóide. Moresco \& Bueno (2007) registraram o táxon em ambiente lêntico com medidas celulares muito próximas as aqui documentadas (12-16 $\mu \mathrm{m}$ compr., 3-6 $\mu \mathrm{m}$ larg.).

\section{Agradecimentos}

Ao Instituto Chico Mendes de Conservação da Biodiversidade na pessoa do Diretor do Parque Nacional do Iguaçu, pelas facilidades concedidas para a realização dos estudos. Ao SISBIO pela autorização concedida para realização da pesquisa na Unidade de Conservação (13134-2). A Fundação Araucária (Chamada 14/2008) e Convênio Fundação Araucária 225/08 (Bolsa de Mestrado).

\section{Literatura citada}

Andrade, R.M. \& Rachou, R. 1954. Levantamento preliminar dos organismos planctônicos e alguns criadouros do Anopheles darlingi Root no sul do Brasil. Revista Brasileira de Malariologia e Doenças Tropicais 6: 481-496.

Bicudo, C.E.M. \& Menezes, M. 2006. Gêneros de algas de águas continentais do Brasil. São Paulo, Editora RiMa, São Carlos.

Bittencourt-Oliveira, M.C. 1997. Fitoplâncton do Rio Tibagi, Estado do Paraná, Brasil: Nostocophyceae, Chlorophyceae, Euglenophyceae, Chrysophyceae e Tribophyceae. Hoehnea 24: 1-20.

Cecy, I.I.T., Moreira, I.M.V. \& Hohmann, E. 1976. Estudo ficológico e químicobacteriológico da água do tanque do passeio público de Curitiba, Estado do Paraná, Brasil. Boletim Museu Botânico Municipal 25: 1-37.

Chodat, R. 1913. Monographie d'algues en culture pure. Matériaux pour la Flore Cryptogamique Suisse 4: 1-266.

Chodat, R.1926. Scenedesmus: étude de génétique, de systématique expérimentale et d'hydrobiologie. Zeitschrif für Hydrologie 3: 71-258.

Comas, G.A. 1996. Las Chlorococcales dulciacuícolas de Cuba. Bibliotheca Phycologica 99, Berlin.

Ferragut, C., Lopes, M.R.M., Bicudo, D.C., Bicudo, C.E.M. \& Vercellino, I.S. 2005. Ficoflórula perifítica e planctônica (exceto Bacillariophyceae) de um reservatório oligotrófico raso (Lago do IAG, São Paulo). Hoehnea 32: 137-184.

Hegewald, E. 1977. Scenedesmus communis Hegewald, a new species and its relation to Scenedesmus quadricauda (Turp.) Bréb. Algological Studies 18: 142-155.

Hegewald, E. 1979. Vergleichende Beobachtungen an Herbarmaterial und Freilandmaterial von Scenedesmus. Algological Studies 24: 264-286.

Hegewald, E. 1989. The Scenedesmus strains of the Culture Collection of the University of Texas at Austin(UTEX).Algological Studies 55: 153-189.

Hegewald, E. 2000. New combinations in the genus Desmodesmus (Chlorophyceae, Scenedesmaceae). Algological Studies 96: 1-18. 
Hegewald, E. \& Silva, P. 1988. Annotated catalogue of Scenedesmus and nomenclaturally related genera, including original descriptions and figures. Bibliotheca Phycologica 80: 1-587.

Holtmann, T. \& Hegewald, E. 1987. Der Einfluß von Nährlösungen auf die Variabilität von Isolaten der Gattung Scenedesmus Untergattung Acutodesmus. Algological Studies 44: 365-380.

Hindák, F. 1990. Studies on the chlorococcal algae (Chlorophyceae), 5. Biologické Prace 36: 1-225.

Komárek, J. \& Fott, B. 1983. Chlorophyceae (Grünalgen), Ordiniung: Chlorococcales. In: G. Huber-Pestalozzi, H. Heynig \& D. Mollenhauer (eds.). Das Phytoplankton des Süsswasser: systematik und biologie. E. Schweizerbart'sche Verlagsbuchlandlung, Stuttgart, pp. 1-1044.

Leite, C.R. 1974. Contribuição ao conhecimento das Chlorococcales (Chlorophyceae) planctônicas do Parque Estadual das Fontes do Ipiranga. Dissertação de Mestrado, Universidade de São Paulo, São Paulo.

Lozovei. A.L. \& Luz, E. 1976. Díptera Culicidae em Curitiba e arredores, 2: alimentação. Arquivos de Biologia e Tecnologia 19: 43-83.

Lozovei, A.L. \& Hohmann, E. 1977. Principais gêneros de microalgas em biótopos de larvas de mosquito de Curitiba, Estado do Paraná, Brasil, 3: levantamento e constatação da ecologia. Acta Biológica Paranaense 6: 123-152.

Moreira Filho, H. \& Moreira, I.M.V. 1972. Observações sobre algas em águas de abastecimento. Tribuna Farmacêutica 40: 14-27.

Moreira Filho, H., Cecy, I.T. \& Moreira, I.M.V. 1976. Diatomáceas da Lagoa Dourada, Estado do Paraná, Brasil. Tribuna Farmacêutica 44: 3-14.

Moresco, C. \& Bueno, N.C. 2007. Scenedesmaceae (Chlorophyceae-Chlorococcales) de um lago artificial urbano: Desmodesmus e Scenedesmus. Acta Scientiarum 29: 289-296.

Nogueira, I.S. 1991. Chlorococcales sensu lato (Chlorophyceae) do Município de Rio de Janeiro e arredores, Brasil: inventário e considerações ecológicas. Dissertação de Mestrado, Universidade Federal do Rio de Janeiro, Rio de Janeiro.

Nogueira, I.S. \& Oliveira, J.E. 2009. Chlorococcales e Ulothricales de hábito colonial de quatro lagos artificiais do município de Goiânia - GO. Iheringia 64: 123-143.

Oliveira, M.D., Train, S. \& Rodrigues, L.C. 1994. Levantamento preliminar do fitoplâncton de rede (exceto Zygnemaphyceae) do Rio Paraná, no Município de Porto Rico, Paraná, Brasil. Revista Unimar 16: 155-173.

Picelli-Vicentim, M.M. 1987. Chlorococcales planctônicas do Parque Regional do Iguaçu, Curitiba, Estado do Paraná. Revista Brasileira Biologia 47: 57-85.

Picelli-Vicentim, M.M., Treuersch, M. \& Domingues, L.L. 2001. Fitoplâncton da Represa do Passaúna, Estado do Paraná, Brasil. Hoehnea 28: 53-76.

Rodrigues, L.C. \& Train, S. 1993. Chlorococcales planctônicas do Lago Alfredo Nyffleler, Maringá, Paraná, Brasil. Unimar 15: 19-35.

Rosa, Z.M. \& Miranda-Kiesslich, A.L. 1988. O gênero Pediastrum Meyen (ChlorococcalesHydrodictyaceae) do sistema lagunar da região litoral do rio Grande do Sul, Brasil. Iheringia 38: 149-169.

Sant'Anna, C.L. 1984. Chlorococcales (Chlorophyceae) do Estado de São Paulo, Brasil. Bibliotheca Phycologica 67: 1-348.

Sant'Anna, C.L. \& Martins, D.V. 1982. Chlorococcales (Chlorophyceae) dos Lagos Cristalino e São Sebastião, Amazonas, Brasil: taxonomia e aspectos ecológicos. Revista Brasileira de Botânica 5: 67-82.

Sant'Anna, C.L., Azevedo, M.T.P. \& Sormus, L. 1989. Fitoplâncton do Lago das Garças, Parque Estadual das Fontes do Ipiranga, São Paulo, SP, Brasil: estudo taxonômico e aspectos ecológicos. Hoehnea 16: 89-131.

Stankiewicz, E.H. 1980. Flórula no conteúdo estomacal do Pseudocurimata gilberti (Quoy e Gaimard 1824). Tese de Doutorado, Universidade Federal do Paraná, Curitiba.

Stankiewicz, E.H., Andrade, L.F. \& Domingues, L.L. 1981. Levantamento ficológico do Rio Iguaçu: algas unicelulares, 1. Surehma 1: 1-76.

Toledo, L. \& Comas, A. 1988. Sobre la variabilidad morfológica y la taxonomia de algunas espécies de Scenedesmus (Chlorellales). Acta Botanica Cubana 57: 1-32. 